Review Article

\title{
The Effect of Art Therapy and Music Therapy on Breast Cancer Patients: What We Know and What We Need to Find Out-A Systematic Review
}

\author{
Justina Kievisiene $\mathbb{D}^{1},{ }^{1}$ Rasa Jautakyte, ${ }^{1}$ Alona Rauckiene-Michaelsson, ${ }^{1}$ \\ Natalja Fatkulina $\left(\mathbb{D},{ }^{2}\right.$ and Cesar Agostinis-Sobrinho $\mathbb{1}^{1}$ \\ ${ }^{1}$ Faculty of Health Sciences, Klaipeda University, Herkaus Manto g. 84, 92294 Klaipeda, Lithuania \\ ${ }^{2}$ Institute of Health Sciences, Faculty of Medicine, Vilnius University, M. K. Čiurlionio g. 21/27, LT-03101, Vilnius, Lithuania \\ Correspondence should be addressed to Justina Kievisiene; justina.kievisiene@gmail.com
}

Received 21 April 2020; Revised 18 June 2020; Accepted 26 June 2020; Published 15 July 2020

Guest Editor: Yuan Xu

Copyright (c) 2020 Justina Kievisiene et al. This is an open access article distributed under the Creative Commons Attribution License, which permits unrestricted use, distribution, and reproduction in any medium, provided the original work is properly cited.

\begin{abstract}
Objective. To systematically review the evidence available on the effects of art therapy and music therapy interventions in patients with breast cancer. Design. Systematic search was conducted in PubMed, EBSCO, and Cochrane Central databases. Articles were scanned using the following keywords: "art therapy" or "music therapy" and "breast cancer" or "breast neoplasms," "breast carcinoma," "breast tumor," and "mammary cancer." Only RCTs published in English, with a control group and experimental group, and presenting pre-/post-therapy results were included. PRISMA guidelines for this systematic review were followed. Results. Twenty randomized controlled trials matched the eligibility criteria. Nine studies evaluated the effect of art therapy, and eleven evaluated the effect of music therapy. Improvements were measured in stress, anxiety, depression reduction, pain, fatigue, or other cancer-related somatic symptoms' management. Overall, the results show that art therapy was oriented towards the effects on quality of life and emotional symptoms while music therapy is the most often applied for anxiety reduction purposes during or before surgeries or chemotherapy sessions. Conclusion. Art and music therapies show effective opportunities for breast cancer patients to reduce negative emotional state and improve the quality of life and seem to be promising nonmedicated treatment options in breast oncology. However, more detailed and highly descriptive single therapy and primary mental health outcome measuring RCTs are necessary to draw an evidence-based advise for the use of art and music therapies.
\end{abstract}

\section{Introduction}

Cancer is the second leading cause of death worldwide, globally accounting for 1 in 6 deaths in 2018 [1] and is likely to become a major obstacle to increasing life expectancy in this century [2]. Breast cancer is the second most often diagnosed cancer type overall and the first in women [3]. Although medical advances in cancer prevention, diagnosis, and treatment continually increase survival rates [4], breast cancer diagnosis is associated with long-term psychological and physical adverse conditions [5]. Cancer diagnosis and treatment procedures are stressful and traumatic experience [6-8]. Emotional responses to cancer diagnosis and ongoing treatment range in symptoms of prolonged psychological distress, depression, and anxiety [9-11]. Women with breast cancer report decreased quality of life [12], encounter cancer-related fatigue [13], and face difficulties in coping with disease and treatment [14]. Together these studies highlight the inseparable burden of cancer diagnosis on the psychological state and the necessity to address oncopatient mental condition.

Medical improvement that extended survival rates and reduced recurrence rates also resulted in the need to efficiently address persistent side effects and emotional consequences, following breast cancer treatment and after treatment period [7]. Breast cancer survivors represent a 
unique group with the highest and longest survival rate $[2,5]$; however, they deal with various treatment-related side effects and usually die not from breast cancer, but from cancer comorbidities $[15,16]$. The improvement of quality of life in cancer patients alongside the mortality reduction become the main targets [17]. Therefore, these are growing appeals for lifestyle interventions that could strengthen positive life experience after breast cancer treatment and emotional adjustment dimension is an inseparable part of it. Integrative oncology is the newly adopted term in scientific literature representing the combination of complementary medicine therapies in conjunction with conventional cancer treatments [18]. These evidence-based interventions provided in cancer treatment centres in addition to conventional treatments address the physical, psychological, and spiritual quality of life of cancer patient [19]. Cancer treatment is not only a traditional medicine issue anymore; growing scientific field shows the importance of combining complementary medicine with target to maintain and improve cancer patient psychological well-being, address emotional distress, improve survival rates [18], and decrease comorbidities that usually arise with physically and emotional unhealthy lifestyles after breast cancer treatment [15]. Literature shows that Contemporary and Alternative Medicine (CAM) is a widespread supportive treatment option in oncology settings comprised of nonmedicated therapies generally aimed at improving patients physical/psychological well-being, increasing body's ability to overcome cancer, and prolonging survival $[20,21]$. CAM includes diverse treatments provided in oncology settings, such as art therapy, music therapy, meditation, hypnosis, yoga, and imagery [22], but in this systematic review we focus on two forms: art and music therapies.

Art therapy is a form of emotional support focusing on difficulties to express psychological distress and difficult feelings, thoughts related to challenging cancer diagnosis, and treatment situation [23]. Recent systematic review evaluated six RCTs and acknowledged that art therapy enhances the psychological state among breast cancer patients [24]. Heterogeneity of outcome for mental health in relatively small number of RCTs assessed in previous systematic review complicates the analysis of the effects of art therapy for breast cancer patients. Therefore, there is an undoubtable need to renew the state of knowledge in this area and analyse the results of the newest RCTs done.

Music therapy is an effective complementary health approach in integrative oncology treatment which provides support for cancer patients. Evidence-based use of music therapy is directed to accomplish physical, emotional, cognitive, and social needs of individuals [25]. Even though recent systematic review show that music therapy is the most advantageous for improving quality of life and reducing anxiety, depression, pain, and fatigue in cancer patients [26], there is no systematic review evaluating the effect of music therapy on breast cancer patient group. To the best of our knowledge, this is the first systematic review analysing the effect of music therapy in breast cancer patient group.

Therefore, in this paper, we systematically review the evidence available on the effects of art therapy and music therapy interventions in patients with breast cancer. We also aim to identify gaps in research which, if taken into account, could help to produce evidence-based solutions for art therapy and music therapy application in breast cancer treatment.

\section{Methods}

We conducted an electronic literature search of the PubMed, EBSCO, and Cochrane Central databases with the following keywords: "art therapy" or "music therapy" and "breast cancer" or "breast neoplasms," "breast carcinoma," "breast tumor," and "mammary cancer" and limited to full-text RCT reports in English. We searched for clinical trials from inception to March 2020. The references of the final included studies were also reviewed. The search was conducted by two investigators (J.K. and R.J.) independently. RCTs published from 2006 till 2020 were screened by titles; duplicates were excluded, and the remaining records were screened by reading abstracts. Studies included assessed complete outcomes (including pretest and posttest) of music and art therapies in breast cancer patient group. We excluded studies reporting multiple therapies and other types of interventions, designed as a study and other than an RCT (e.g., review, survey, case study, etc.) or evaluating the effect in breast cancer group with other diseases as well as other cancer types. We performed a targeted search as shown in Figure 1 using the terms "art therapy" or "music therapy" and "breast cancer." We followed the PRISMA guidelines for this systematic review.

\section{Results}

3.1. Art Therapy. We included nine RCT studies (Table 1) that focused on the effect of art therapy in breast cancer patient group involving 540 participants. Six identified RCTs randomized women to the art therapy group and intervention absent control group, and three RCTs used control group with another intervention (two educational support groups or one SHAM painting group). Four studies evaluated mindfulness-based art therapies (MBAT) that used some relaxation techniques together with art therapy, two enrolled individual art therapy sessions, one study modified intervention to brief art therapy sessions, and two referred to more traditional art therapy framework. The duration of interventions was between 4 and 12 weeks. Art therapy research was oriented towards effects on quality of life and emotional symptoms.

3.2. Music Therapy. We found 11 randomized controlled trials (Table 2) with 1002 participants where the effectiveness of music intervention for women with breast cancer were documented. Studies varied in methodologies: the majority of studies used standard RCT format with an experimental group and no intervention control group (seven RCTs), two studies were comprised of three comparative groups (two different music intervention groups and one control), one used active control group who listened to ambient music and intervention group, and one study compared intervention 


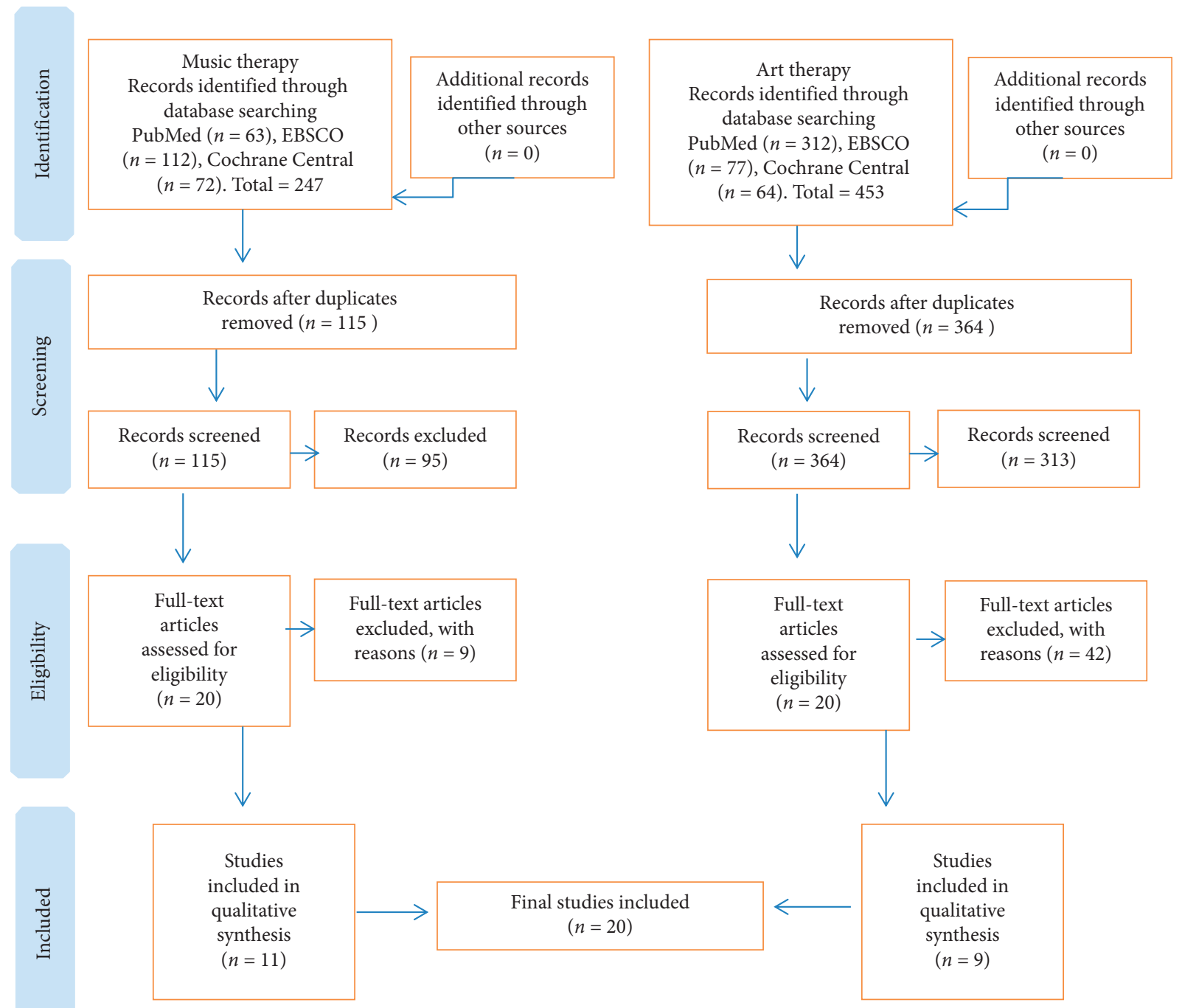

FIGURE 1: Flowchart of citations and articles through the phases of screening and eligibility evaluation.

group with control group where patients received psychosocial conversations. Studies varied greatly on the performance (from listening to prepared music set, singing together to listening to live song performance), duration (from $5 \mathrm{~min}$ intervention to $2.5 \mathrm{~h}$ session), and frequency (from single intervention to 24-week long music therapy sessions 5 times a week). Mostly music therapy interventions were implemented in the preoperative or during chemotherapy treatment seasons with anxiety reduction aim.

\section{Discussion}

\subsection{What Do We Know?}

4.1.1. Art Therapy. Art therapy is a category of complementary interventions applied in oncological settings and intended to ease or control the physical and psychological symptoms caused by cancer and cancer treatment [47]. Art-making in a therapeutic setting alleviates emotion expression and communication, therefore providing the cancer patient with the opportunity to reduce psychological discomfort, cope with anxiety and depression, or to receive adequate social support [48]. In general, the expectation from art therapy as a complementary form of oncodisease treatment is to improve the quality of life of cancer patients. The most recent and comprehensive study analysed the effect of art therapy for emotional symptom reduction [35]. The study evaluated emotion processing in art therapy (art therapy group) vs. SHAM (mandala group) that painted prefabricated shapes without explicit focus on emotion. Between-group comparison showed the large effect of art therapy on depression reduction and increasing of emotional awareness and emotional acceptance. A small effect for specific to cancer physical symptoms was also detected. Authors report the emotion processing in art therapy group to be a potential mechanism in reduction of depression symptoms and physical symptoms in cancer patients [35]. Another study also evaluated the effect of AT for emotional symptoms expressed by breast cancer patients [33] and found significantly decreased depressive and anxiety symptoms in the intervention group. Results also indicated the increase in the quality of life in the art therapy group. 
TABLE 1: Reviewed studies in art therapy according to sample, intervention, outcomes, and main findings.

\begin{tabular}{|c|c|c|c|c|c|}
\hline $\begin{array}{l}\text { Study } \\
\text { author, year }\end{array}$ & Sample & $\begin{array}{l}\text { Intervention: content, } \\
\text { duration, and frequency }\end{array}$ & $\begin{array}{c}\text { Outcome } \\
\text { indicators: } \\
\text { Primary [1] } \\
\text { Secondary [2] }\end{array}$ & Scale & $\begin{array}{c}\text { Main findings and effect } \\
\text { sizes (Cohen's } d \text { if applicable) }\end{array}$ \\
\hline $\begin{array}{l}\text { Öster et al., } \\
2006 \text { [27] }\end{array}$ & $\begin{array}{c}N=41(37-69 \\
\text { years). } \\
\text { IntGr } n=20, \\
\text { ConGr (not } \\
\text { described) } n=21\end{array}$ & $\begin{array}{l}\text { (i) Individual counseling } \\
\text { session that involved } \\
\text { semistructured creative art } \\
\text { therapy experience and guided } \\
\text { meditation to help exploration } \\
\text { of spiritual themes } \\
\text { (ii) } 4 \text { weeks (one session for } \\
1 \text { h/week) }\end{array}$ & $\begin{array}{l}\text { Emotional [1] } \\
\text { expression } \\
\text { Spirituality [1] } \\
\text { Psychological } \\
\text { well-being [1] }\end{array}$ & $\begin{array}{l}\text { EACS } \\
\text { ESI-R } \\
\text { POMS }\end{array}$ & 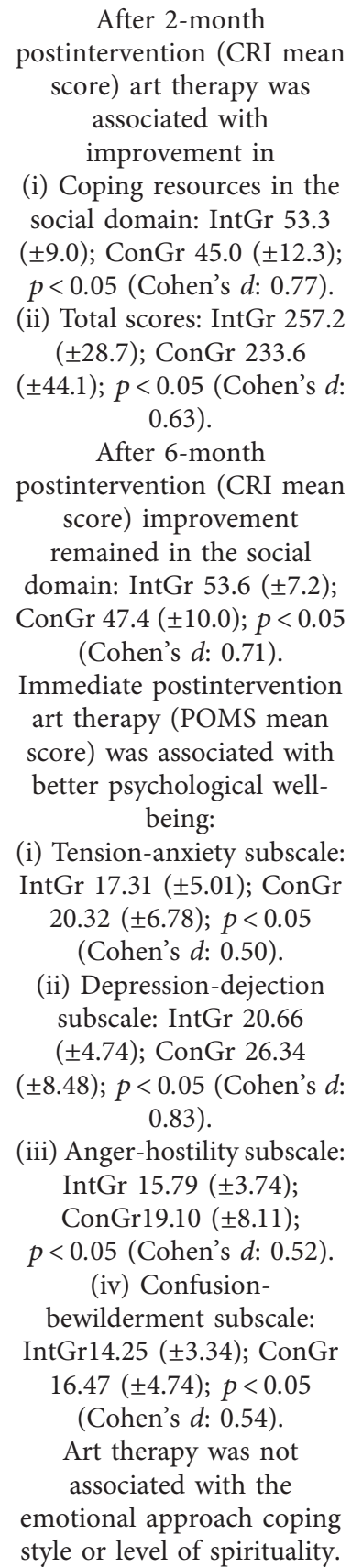 \\
\hline
\end{tabular}


TABle 1: Continued.

\begin{tabular}{|c|c|c|c|c|c|}
\hline $\begin{array}{l}\text { Study } \\
\text { author, year }\end{array}$ & Sample & $\begin{array}{l}\text { Intervention: content, } \\
\text { duration, and frequency }\end{array}$ & $\begin{array}{c}\text { Outcome } \\
\text { indicators: } \\
\text { Primary [1] } \\
\text { Secondary }[2]\end{array}$ & Scale & $\begin{array}{c}\text { Main findings and effect } \\
\text { sizes (Cohen's } d \text { if applicable) }\end{array}$ \\
\hline $\begin{array}{l}\text { Svensk et al., } \\
2009 \text { [29] }\end{array}$ & $\begin{array}{c}\quad N=41 \\
\text { IntGr (mean age } \\
\text { 59) } n=20 \text {, ConGr } \\
\text { (not described, } \\
\text { mean age 55) } n=21\end{array}$ & $\begin{array}{l}\text { (i) Individual sessions of art } \\
\text { therapy, phenomenological } \\
\text { method } \\
\text { (ii) } 5 \text { weeks (one session for } \\
1 \mathrm{~h} / \text { week) }\end{array}$ & $\begin{array}{l}\text { Quality of life [1] } \\
\text { General health [1] }\end{array}$ & $\begin{array}{c}\text { WHOQOL- } \\
\text { BREF } \\
\text { EORTC-QLQ- } \\
\text { BR23 }\end{array}$ & $\begin{array}{c}\text { After 6-month } \\
\text { postintervention } \\
\text { (WHOQOL-BREF mean } \\
\text { score) art therapy was } \\
\text { associated with } \\
\text { improvement in } \\
\text { (i) Overall quality of life: } \\
\text { IntGr } 85.00( \pm 12.57) \text {; ConGr } \\
67.50( \pm 20.03) ; p<0.05 \\
\text { (Cohen's } d: 1.05) . \\
\text { (ii) General health: IntGr } \\
71.25( \pm 20.32) ; \text { ConGr } 55.00 \\
( \pm 23.79) ; p<0.05 \text { (Cohen's } \\
d: 0.73) .\end{array}$ \\
\hline
\end{tabular}

(iii) Environmental domain: IntGr $74.69( \pm 8.54)$; ConGr 68.59; ( \pm 11.58$) ; p<0.05$

(Cohen's $d: 0.60$ ).

After 4 months

postintervention (SCL-90

means score) art therapy was associated with improvement in:

(i) Depression symptoms: IntGr $0.22( \pm 0.21)$; ConGr

$0.44( \pm 0.38) ; p<0.05$

(Cohen's $d$ : 0.72).

Thyme et al., years). therapy, phenomenological 2009 [30]

IntGr $n=20$

ConGr (no

intervention) $n=21$

(ii) 5 weeks (one session for $1 \mathrm{~h} /$ week)

$N=18(52-77$ years).

Monti et al., 2012 [31]

IntGr $n=8$, ConGr

(educational support program) $n=10$

$N=191(37-69$ years).

Monti et al., 2013 [32]
IntGr $n=93$, ConGr

(educational support program) $n=98$
Perceived self-

image [1]

Psychiatric

symptoms [1]

Psychosocial

variables [2]

Treatment

modalities [2]
SASB

SCL-90

(ii) anxiety symptoms: IntGr

$0.16( \pm 0.19)$; ConGr 0.40

$( \pm 0.39) ; p<0.05$ (Cohen's $d$ : $0.78)$.

(iii) Somatic symptoms: IntGr0.38 $( \pm 0.39)$; ConGr $0.72( \pm 0.66) ; p<0.05$

(Cohen's $d: 0.63$ ).

(iv) General severity symptom: IntGr 0.19 $( \pm 0.16)$; ConGr $0.34( \pm 0.28)$; $p<0.05$ (Cohen's $d$ : 0.66).

Art therapy was associated with observed effect on regional $\mathrm{CBF}$ in multiple brain areas: the left insula, right amygdala, right

The fMRI imaging protocol hippocampus, and bilateral caudate (structures involved in meditation tasks as well as emotional processing related to anxiety).

(i) Group sessions of mindfulness-based art therapy (ii) 8 weeks (1 time a week, duration not described).
Psychosocial stress [1]

Anxiety [1] resting in cerebral [1]

Stress-related somatic complaints [1]

Health-related quality of life [1]
SCL-90-R

SF-36

BSI-18
Art therapy was associated with improved overall outcomes in intervention group participants with high stress levels at baseline. 
Table 1: Continued.

\begin{tabular}{|c|c|c|c|c|c|}
\hline $\begin{array}{l}\text { Study } \\
\text { author, year }\end{array}$ & Sample & $\begin{array}{l}\text { Intervention: content, } \\
\text { duration, and frequency }\end{array}$ & $\begin{array}{l}\text { Outcome } \\
\text { indicators: } \\
\text { Primary }[1] \\
\text { Secondary }[2]\end{array}$ & Scale & $\begin{array}{l}\text { Main findings and effect } \\
\text { sizes (Cohen's d if applicable) }\end{array}$ \\
\hline $\begin{array}{l}\text { Jalambadani } \\
\text { and Borji, } 2019 \\
{[34]}\end{array}$ & $\begin{array}{c}N=124(40-60 \\
\text { years). } \\
\text { IntGr } n=50, \\
\text { ConGr (waitlisted) } \\
\quad n=50\end{array}$ & $\begin{array}{l}\text { (i) Group sessions of } \\
\text { mindfulness-based art therapy } \\
\text { (ii) } 12 \text { weeks (one session for } \\
45 \mathrm{~min} / \text { week). }\end{array}$ & $\begin{array}{c}\text { Depression [1] } \\
\text { Anxiety [1] } \\
\text { Quality of life [1] }\end{array}$ & $\begin{array}{l}\text { PAI: Anxiety } \\
\text { and depression } \\
\text { subscales } \\
\text { EORTC-QLQ- } \\
\text { C30 }\end{array}$ & 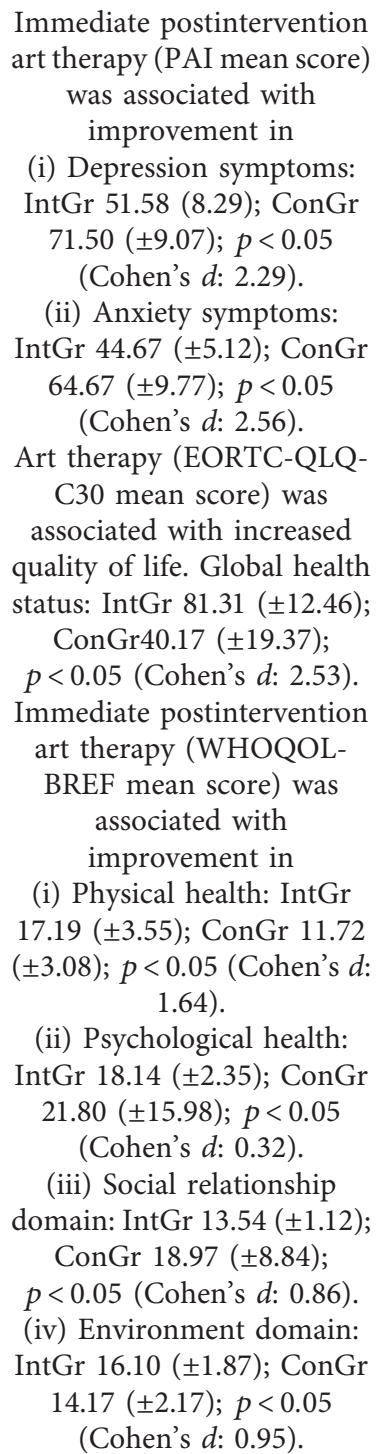 \\
\hline
\end{tabular}


TABLE 1: Continued.

\begin{tabular}{|c|c|c|c|c|c|}
\hline $\begin{array}{l}\text { Study } \\
\text { author, year }\end{array}$ & Sample & $\begin{array}{l}\text { Intervention: content, } \\
\text { duration, and frequency }\end{array}$ & $\begin{array}{c}\text { Outcome } \\
\text { indicators: } \\
\text { Primary }[1] \\
\text { Secondary }[2]\end{array}$ & Scale & $\begin{array}{l}\text { Main findings and effect } \\
\text { sizes (Cohen's d if applicable) }\end{array}$ \\
\hline $\begin{array}{l}\text { Czamanski- } \\
\text { Cohen et al., } \\
2019[35]\end{array}$ & $\begin{array}{c}N=20(36-70 \\
\text { years). } \\
\text { IntGr } n=10, \\
\text { ConGr (SHAM art } \\
\text { therapy) } n=10\end{array}$ & $\begin{array}{l}\text { IntGr: } \\
\text { (i) Group art therapy } \\
\text { (ii) } 8 \text { weeks (one session for } \\
90 \text { min/week) } \\
\text { ConGr: } \\
\text { (i) Group SHAM art therapy } \\
\text { (mandala painting) } \\
\text { (ii) } 8 \text { weeks (one session for } \\
1 \text { h/week) }\end{array}$ & $\begin{array}{c}\text { Emotion } \\
\text { processing [1] } \\
\text { Depressive } \\
\text { symptoms [1] } \\
\text { Physical } \\
\text { symptoms [1] }\end{array}$ & $\begin{array}{l}\text { The levels of } \\
\text { emotional } \\
\text { awareness scale } \\
\text { The acceptance } \\
\text { of emotions } \\
\text { scale (AE) } \\
\text { CES-D } \\
\text { BCPT }\end{array}$ & $\begin{array}{l}\text { Immediate postintervention } \\
\text { art therapy was associated } \\
\text { with improvement in } \\
\text { (i) Acceptance of emotions } \\
\text { (AE mean score): IntGr } \\
95.00( \pm 18.10) \text {; ConGr } \\
103.00( \pm 12.11) ; p<0.05 \\
\text { (Cohen's } d: 0.52) \text {. } \\
\text { (ii) Depressive symptoms } \\
\text { (CES-D mean score): IntGr } \\
8.0( \pm 2.9) \text {; ConGr } 22.7 \\
( \pm 15.0) ; p<0.05 \text { (Cohen's } d \text { : } \\
1.36) \text {. } \\
\text { (iii) Emotional awareness } \\
\text { (the levels of emotional } \\
\text { awareness scale mean score): } \\
\text { IntGr } 30.00( \pm 3.37) \text {; ConGr } \\
21.20( \pm 6.54) ; p<0.05 \\
\text { (Cohen’s } d \text { : } 1.69) \text {. }\end{array}$ \\
\hline
\end{tabular}

IntGr: intervention group; ConGr: control group.

The effect of art therapy on the quality of life was evaluated in three more RCTs showing significant improvement in physical health, psychological, social, and environmental aspects in art therapy group without changes in the control group [34] and positive changes overall specific to cancer health [33], whereas one study revealed no significant between-group changes in overall quality of life, except in high stress level cancer patient subgroup where MBAT was shown to be significantly more effective [32]. The same nonsignificant effect in between-group comparison of MBAT was found in terms of psychosocial stress [32]; however, previous study with comparison to waitlist control group revealed significant improvements in psychosocial stress and quality of life [31]. The positive effect of art therapy on breast cancer patients quality of life has been also shown by earlier research [29] together with significant effect of art therapy on increased total health or more favorable body image or future perspectives. Initial research in this specific area started in 2006 with studies in general evaluating the effect of art therapy on participants' coping resources $[27,28]$. None of them found statistically significant effect of art therapy in terms of emotional coping or enhancement of level of spirituality [28]; however, art therapy was shown to have a significant effect on social coping domain [27] and was associated with increased psychological well-being in terms of tension, anxiety, or anger reduction [28]. The effect of art therapy on psychological health was also shown by another study [30] demonstrating the long-term effect of art therapy on significant lowering of depression, anxiety symptoms and less general health symptoms. Based on this 2019 systematic literature review on the efficacy of art therapy in breast cancer patients, some important issues should be noted.
Firstly, studies use broad and nonspecific definitions of art therapy and include various perspectives and activities under art therapy category. Even though art therapy should be addressed as a form of psychotherapy with special attention to the use of visual art-makings for emotion expression [49], others state that this is a term for therapies that involve not only visual art, but also music, dance, poetry, and drama [50, 51]. Moreover, some researchers name the art therapy as "creative arts therapy" [28] although it is described as traditional art therapy session with the usage of various painting and drawing supplies and tablets to explore the patient's emotional expression and improve psychological well-being. Usage of different terminology and lack of clear explanation of interventions applied may lead to improper classifications of studies in systematic reviews and may induce misinterpretation of effect results in meta-analysis (e.g., [52]). Second, randomized controlled trials in breast cancer show variety in outcome measure, ranging from depressive symptoms, quality of life or physical symptom measurement [33-35], psychological well-being and emotional coping variations [28], self-image or psychiatric symptoms [30] to changes in cerebral blood flow and anxiety [31]. Taking into consideration the array of different outcome measures, the real effect of art therapy in breast cancer setting may remain vague; therefore, more RCTs are needed to clarify the art therapy effect in this specific sample. Third, this systematic review shows a lack of and slow study progress in art therapy in breast cancer section. The previous systematic review on the efficacy of art therapy on mental health outcomes among breast cancer patients [24] resulted in 6 RCTs identified, as this systematic review resulted in 9 RCTs regarding the issue evaluated. Even though 
TABLE 2: Reviewed studies in music therapy according to sample, intervention, outcomes, and main findings.

\begin{tabular}{|c|c|c|c|c|c|}
\hline $\begin{array}{l}\text { Study } \\
\text { author, year }\end{array}$ & Sample & $\begin{array}{l}\text { Intervention: content, } \\
\text { duration and frequency }\end{array}$ & $\begin{array}{c}\text { Outcome } \\
\text { indicators: } \\
\text { Primary [1] } \\
\text { Secondary [2] }\end{array}$ & Scale & $\begin{array}{c}\text { Main findings and effect } \\
\text { sizes (Cohen's d if } \\
\text { applicable) }\end{array}$ \\
\hline
\end{tabular}

No significant differences in quality of life or

$N=70$ (26-77 years).

Hanser IntGr $n=20$, ConGr

et al., 2006 (usual oncology and

[36] supportive care) $n=22$

$$
N=60
$$

Bulfone

et al., 2009

[37]

IntGr (mean age $49.2 \pm 6.9) n=30$,

ConGr (standard assistance, mean age $52.7 \pm 6.1) n=30$ (i) Individual sessions with music therapist

(ii) Up to 15 weeks (three 45 min sessions)

(i) Listening to pretaped and recorded music in earphones

(ii) $15 \mathrm{~min}$ of music

listening while waiting for the call for chemotherapy
Anxiety [1]

Quality of life [1

Psychological distress [1]

Cardiovascular arousal [2]

Relaxation, comfort, mood [2]

FACT-G plus FACITSp subscale

HADS

VAS

STAI-Y

(i) Listening to pretaped

Binns-

Turner

et al., 2011

[38]

$N=30$ (42-70 years). music in the perioperative

IntGr $n=15$, ConGr

(standard care) $n=15$

$$
\text { period }
$$

(ii) Duration not described

(i) Self-selected music

$N=120$ (25-65 years) IntGr $n=60$, ConGr (routine nursing

Li et al., 2011 [39]
Anxiety [1]

Hemodynamics [1]

Pain [1]

SAI

VAS

SF-MPQ (including

Pain [1]

PRI-Total, VAS, PPI)

General questionnaire care/no intervention) $n=60$ from preselected 202

items through MP3

$$
\text { player }
$$

(ii) Listening to music twice a day (30 min per session), in the morning and in the evening psychological distress observed.

Music therapy was associated with improvement in secondary outcomes immediate after sessions: relaxation, comfort, happiness, heart rate $(p<0.05)$.

Immediately after music therapy (STAI-Y mean score) reduction in anxiety state $(p<0.05)$ was observed.

Postoperatively music therapy (SAI mean score) was associated with improvement in

(i) Levels of MAP : IntGr 83.6 ( \pm 13.0$)$, ConGr 96.6

$( \pm 14.3) ; p<0.05$ (Cohen's d: 0.95).

(ii) Anxiety symptoms: IntGr 30.7 ( \pm 12.3$)$, ConGr 49.7 ( \pm 18.9$) ; p<0.05$ (Cohen's $d: 1.19$ ).

(iii) Pain symptoms: IntGr $41.5( \pm 30.2)$, ConGr 64.9 $( \pm 20.9) ; p<0.05$ (Cohen's $d: 0.90)$.

Music therapy (PRI-total mean score) was associated with improvement in pain symptoms in three measured time points:

(i) The day before discharge from hospital: IntGr $2.25( \pm 1.17)$; ConGr $4.70( \pm 1.50) ;<0.05$ (Cohen's $d: 1.82$ ).

(ii) The second time of admission to hospital for chemotherapy: IntGr 1.72 $( \pm 1.32)$; ConGr 4.17 $( \pm 1.34) ; p<0.05$ (Cohen's $d: 1.84)$

(iii) The third time of admission to hospital for chemotherapy: IntGr 0.71

$( \pm 0.69)$; ConGr 2.62

( \pm 0.96$), p<0.05$ (Cohen’s $d: 2.28)$. 
TABle 2: Continued.

\begin{tabular}{|c|c|c|c|c|c|}
\hline $\begin{array}{l}\text { Study } \\
\text { author, year }\end{array}$ & Sample & $\begin{array}{l}\text { Intervention: content, } \\
\text { duration and frequency }\end{array}$ & $\begin{array}{l}\text { Outcome } \\
\text { indicators: } \\
\text { Primary [1] } \\
\text { Secondary }[2]\end{array}$ & Scale & $\begin{array}{c}\text { Main findings and effect } \\
\text { sizes (Cohen's d if } \\
\text { applicable) }\end{array}$ \\
\hline
\end{tabular}

Music therapy (SAI mean score) was associated with improvement in anxiety in three measured time periods:

(i) The day before discharge from hospital after radical mastectomy: IntGr 37.77 ( \pm 5.96$)$, ConGr 42.35 ( \pm 6.09$)$;

Li et al., 2012 [40]

As above

As above

Anxiety [1]

SAI

General questionnaire

$p<0.05$ (Cohen's $d: 0.76$ )

(ii) The second time of admission to hospital for chemotherapy: IntGr 34.39 ( \pm 4.26$)$; ConGr 43.10 ( \pm 6.07$) ; p<0.05$ (Cohen's $d: 1.66$ ).

(iii) The third time of admission to hospital for chemotherapy: IntGr 30.87 ( \pm 2.71 ); ConGr 40.35 ( \pm 4.44$) ; p<0.05$

(Cohen's $d: 2.58$ ).

Music therapy (ZSDS mean score) was associated with improvement in depression in three measured time periods:

(i) The day before discharge from hospital after radical mastectomy: IntGr $32.20( \pm 4.73)$, ConGr $35.76( \pm 5.80)$;

Zhou et al., 2011 [41]

As above

As above
Depression [1] Duration of hospital stay [1]
ZSDS

General questionnaire $p<0.05$ (Cohen's $d: 0.67$ )

(ii) The second time of admission to hospital for chemotherapy: IntGr 30.00 ( \pm 4.89$)$; ConGr $35.50( \pm 4.90) ; p<0.05$

(Cohen's $d$ : 1.12).

(iii) The third time of admission to hospital for chemotherapy: IntGr 25.67 ( \pm 2.74$)$; ConGr 32.15 ( \pm 3.86$) ; p<0.05$ (Cohen's $d: 1.93$ ).

Postintervention music therapy ("Emotion
Stress [1] Anxiety [1] IntGr $n=31$, ConGr intervention of music

et al., 2013

[42] (standard therapy and emotional expression. psychosocial care) $n=31$
Depression [1] Anger [1]

"Need for help" variable [1]
"Emotion thermometers tool" thermometers tool" mean score) was associated with improvement in stress, anxiety, depression, and anger $(p<0.05)$ in the experimental group. 
TABle 2: Continued.

\begin{tabular}{|c|c|c|c|c|c|}
\hline $\begin{array}{l}\text { Study } \\
\text { author, year }\end{array}$ & Sample & $\begin{array}{l}\text { Intervention: content, } \\
\text { duration and frequency }\end{array}$ & $\begin{array}{c}\text { Outcome } \\
\text { indicators: } \\
\text { Primary [1] } \\
\text { Secondary [2] }\end{array}$ & Scale & $\begin{array}{c}\text { Main findings and effect } \\
\text { sizes (Cohen's d if } \\
\text { applicable) }\end{array}$ \\
\hline
\end{tabular}

Music therapy (GA-VAS mean score) was associated with

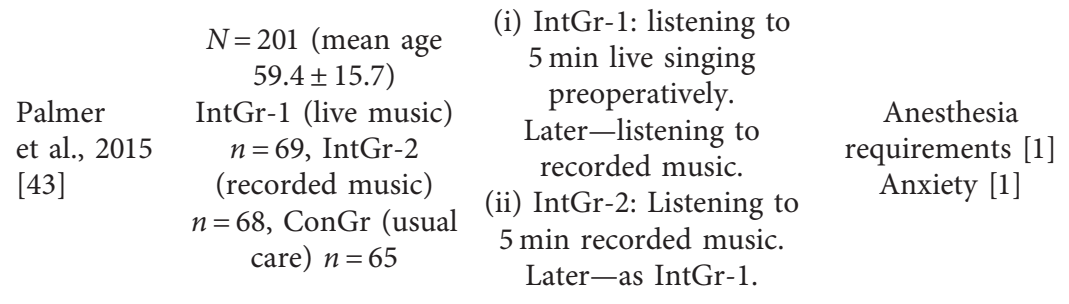

$N=99$ (27-82 years) (i) Listening to pretaped IntGr-1 (Nevasic Nevasic music (IntGr-1)

Moradian et al., 2015 [44] group) $n=34$. IntGr-2 (music group) $n=32$, ConGr (no intervention) $n=33$

$N=60$ (mean age

Karadag

et al., 2019

[45] $59.40 \pm 13.28$ years) IntGr $n=30$, ConGr (no intervention) $n=30$ (i) Pretaped and recorded (ii) 5 weeks ( 5 times a week for $20-40 \mathrm{~min}$ ) music on MP3 player
Frequency and duration of nausea and amount of vomiting [1] Quality of life [2]
Anxiety [1] Depression [2] Comfort level [1]
Rhodes index of nausea, vomiting and retching (INVR) EORTC-QLQ-C30 EORTC-QLQ-BR23

improvement in anxiety symptoms:

(i) Live music group versus control: IntGr 40.7 ( \pm 36.7$)$; ConGr 57.0

$( \pm 46.9) ; p<0.05$ (Cohen’s $d: 0.39)$.

(ii) Recorded music group versus control: IntGr 38.0 $( \pm 32.5)$; ConGr 57.0

$( \pm 46.9) ; p<0.05$ (Cohen’s $d: 0.47)$.

Music therapy was not associated with frequency or duration of nausea and vomiting experiences.

\section{Music therapy (HADS mean score) was associated with improvement in}

(i) Anxiety symptoms: IntGr $5.20( \pm 2.83)$, ConGr 8.59 ( \pm 3.30$) ; p<0.05$

HADS (Cohen's $d: 1.10$ ).

\section{RTCQ}

questionnaire for sociodemographic

and disease characteristics

(ii) Depression symptoms:

IntGr $4.13( \pm 1.85)$; ConGr

$8.33( \pm 4.02) ; p<0.05$

(Cohen's $d: 1.34$ ).

Music therapy (RTCQ mean score) was associated with

improvement in comfort levels: IntGr 119.03

$( \pm 11.90)$; ConGr 96.53 $( \pm 16.64) ; p<0.05$ (Cohen's $d: 1.55)$.

Music therapy (TRSC mean score) was associated with

(i) Pretaped and recorded
music on MP3 player

(ii) 24 weeks (five $30 \mathrm{~min}$ sessions per week)
[1]

Symptom severity

Pain intensity [2]

Perceived fatigue

[2]
TRSC NRS-101 MFSI- improvement in symptom SF-C severity, pain intensity, and fatigue $(p<0.05)$ after 6,12 , and 24 weeks of intervention.

${ }^{\times}$IntGr: intervention group; ConGr: control group.

methodological variations across these identified studies were huge, it should be stated that there is uncountable positive impact of art therapy on overall psychological and physical state of breast cancer patients.
4.1.2. Music Therapy. Music therapy is a health discipline that involves using music and conducting musical activities to treat individuals with specific physical, emotional, cognitive, and social needs [26]. Goals in music and medicine in general may be summarized according to the following: 
elimination of stress and anxiety; elimination of pain; elimination of depression, helplessness; and enhancement of immune functioning [53]. Due to the effects on psychological and some physiological states' management, music therapy is also recognized as a complementary, evidencebased treatment in oncology setting and, in general, aims to increase relaxation and calmness [54].

Results of this systematic review indicate that music therapy was mostly researched for anxiety reduction targets and was predominantly carried out during chemotherapy/ radiotherapy course or in preoperative, perioperative, or postoperative period. For example, listening to music stored onto the MP3 players two times a day (for $30 \mathrm{~min}$ ) following radical mastectomy and the two chemotherapy periods reduced anxiety [39]. Further, significant reduction in anxiety scores was reached with music therapy intervention during the waiting for chemotherapy time. Listening for tapped musical themes for $15 \mathrm{~min}$ before chemotherapy session reduced breast cancer patient's anxiety, while anxiety increase was observed in the intervention free control group [37]. Preoperative anxiety was also significantly lowered and after music therapy applied before surgery [43]. Moreover, listening intervention applied during radiation therapy not only significantly decreased anxiety and depression, but also increased comfort status of the women receiving treatment [45].

The effect of reducing negative emotions during the administration of chemotherapy in terms of stress, depression, anxiety, and anger was reached after single group session of music therapy and emotional expression (lasting 2.5 hours) [42]. Similar results were shown after 45 -minute lasting music therapy sessions (3 times) with significant improvements in reported comfort, relaxation, and happiness and lowered physiologic stress arousal (decreased heart rate). However, the observed results show immediate effect; no significant differences at psychological distress were found over time [36]. In another study, music therapy also was associated not only with reduced depression, but also with reduced duration of hospital stay after radical mastectomy [41].

Another focus of music therapy in breast cancer patient group lays on pain management. Perioperative music therapy was proven to be an effective intervention for pain management (as well as anxiety reduction) [38]. These findings are consistent with another RCT indicating pain reduction effect of music therapy after surgery [39]. Recent study showed that even home-based music therapy may have lasting effect (up to 24 weeks) not only on pain intensity, but also on overall and general fatigue, emotional fatigue, and vigor [46]. Besides anxiety or depression evaluation, two studies also measured the effect of music therapy on nausea and vomiting [45] and sedative requirements [43], but could not confirm associations between them. Despite being statistically significant, less use of antiemetics after listening to Navastic music was indicated [44].

Overall, our analysis of the research studies on music therapy interventions during the treatment of breast cancer patients, including surgical, chemotherapeutic, or radiotherapeutic treatments, indicates their effects on the following outcomes: anxiety, depression, stress, pain, and quality of life. Music intervention is significant for its convenience, noninvasiveness, and high applicability. $\mathrm{Mu}-$ sical intervention can be performed anywhere and it does not require costly, technologically advanced equipment. However, substantial diversity was found among these studies. The different methodologies and different timing are the main reasons for the diversity. Because of the limitations of existing studies, there is a need for future music intervention research.

\subsection{What Do We Need to Find Out?}

4.2.1. Art Therapy. Results of this systematic review show that art therapy is an efficient and promising method in the alteration of breast cancer patient physical and emotional health. However, there is a huge diverseness of evidence across trials due to variation not only in study components (number or respondents, amount and duration of intervention sessions, and individual vs. group intervention), but also in measures used to assess outcomes (e.g., cancerrelated health or quality of life vs. general health or quality of life, etc.). Moreover, with the purpose to reveal clear effect of art therapy, there is a need to use intervention absent control group and our systematic review shows that 3 of 9 used other intervention group as a control group and both reveal positive effects for cancer patient group. Even more importantly, one of the studies found no significant differences between groups [32]; therefore, the effect of art therapy becomes even more vague. Heterogeneity across intervention methods also limits the investigation of the true effect of art therapy as there is no generally accepted standards or guidance ruling the implementation of art therapy, therefore decreasing the repeatability and reliability of the studies. Consequently, there is a need for highly descriptive and sophisticated RCT with outcome measures that are most in line with this specific breast cancer theme.

4.2.2. Music Therapy. Since music therapy has no national or international guidelines, the main problematic area is variety and knowledge interpretation in many aspects, starting from description and identification of the music therapy and finishing with application details. First of all, as this systematic review shows, music therapy has many names: "music intervention," "music listening intervention," "home-based music intervention," "preoperative music," etc. Their variety of definitions of interventions applied leaves theoretical misunderstanding in the most basic level-whether listening for tapped music on MP3 player is a music therapy? If not, then what researchers are evaluating, the effect of listening to songs or just a result of music as a distracting object, which could be replaced, e.g., by movie watching? Further, many RCTs have shown positive effect of music therapy/intervention/listening to elevating psychological distress in general, but they differed in performance 
greatly. Some of them were studying only listening music on MP3 (or other device), while some music intervention were implemented with music therapist or clinical psychologist; other therapists even sang to patients, while in other studies patients sang themselves. Despite that, studies evaluated also revealed a great variety in duration of music therapy overall and single time, the variety and no scientific agreement among pieces of music used for music therapy, and differences in the music selection nature (e.g., prepared by researcher or selected by patient). Taking into account sample size issues (some of studies used relatively small sample), inaccuracies in determining the short- versus long-term effect, and significant differences in application, there is a clear need for more studies of high methodological quality with reasonable and systematic description of interventions applied.

Several limitations in this study should be considered and caution should be taken in the interpretation of the findings: first, due to the small RCT number in the area of art and music therapies in breast cancer group; second, due to the heterogeneity of therapy methods and outcomes involved, since all studies involved in this systematic review combine their own methodology, time, and number of therapies overall.

\section{Conclusion}

This systematic review provides a comprehensive overview of the relationship between art and music therapies and biopsychosocial outcomes on patients with breast cancer. The main results demonstrated that both therapies are effective in the reduction of negative emotional states (e.g., anxiety, depression, or psychological distress level), increase quality of life, and may reduce pain and fatigue related to cancer treatment. More studies, especially focusing on expressively described and scientifically based research methodology, are needed to increase the confidence levels of our findings.

\section{Additional Points}

Breast cancer is the most often diagnosed cancer in women and needs an integrative oncology approach in order to reach the best physical and psychological outcomes. Medical advances prolonged survival; however, breast cancer diagnosis and treatment induce long-term mental health difficulties. The scientific interest in contemporary and alternative medicine in oncology settings has greatly increased during recent years and is widely used to reduce mental distress and enhance the quality of life. Art and music therapies are a safe alternative approach in breast cancer treatment.

\section{Conflicts of Interest}

The authors declare that they have no conflicts of interest regarding the publication of this paper.

\section{References}

[1] B. A. Given, C. W. Given, B. A. Given, and C. W. Given, "The burden of cancer caregivers," Cancer Caregivers, vol. 2018, pp. 20-33, 2019.

[2] M. Lambertini, P. Aftimos, A. Gombos, A. Awada, and M. Piccart, "Breast cancer," Side Effects of Medical Cancer Therapy, Springer Nature, Basel, Switzerland, 2018.

[3] F. Bray, J. Ferlay, I. Soerjomataram, R. L. Siegel, L. A. Torre, and A. Jemal, "Global cancer statistics 2018: GLOBOCAN estimates of incidence and mortality worldwide for 36 cancers in 185 countries," CA: A Cancer Journal for Clinicians, vol. 68, no. 6, pp. 394-424, 2018.

[4] C. Allemani, T. Matsuda, V. Di Carlo et al., "Global surveillance of trends in cancer survival 2000-14 (CONCORD3): analysis of individual records for 37,513,025 patients diagnosed with one of 18 cancers from 322 population-based registries in 71 countries," Lancet, vol. 391, no. 10125, pp. 1023-1075, 2018.

[5] B. I. Bodai and P. Tuso, "Breast cancer survivorship: a comprehensive review of long-term medical issues and lifestyle recommendations," The Permanente Journal, vol. 19, no. 2, pp. 48-79, 2015.

[6] M. Bourdon, M. Blanchin, M. Campone et al., "A comparison of posttraumatic growth changes in breast cancer and melanoma," Health Psychology, vol. 38, no. 10, pp. 878-887, 2019.

[7] M. J. Cordova, M. B. Riba, and D. Spiegel, "Post-traumatic stress disorder and cancer," The Lancet Psychiatry, vol. 4, no. 4, pp. 330-338, 2017.

[8] A. Romeo, M. Di Tella, A. Ghiggia, V. Tesio, R. Torta, and L. Castelli, "Posttraumatic growth in breast cancer survivors: are depressive symptoms really negative predictors?" Psychol Trauma, vol. 12, no. 3, pp. 244-250, 2020.

[9] A. Hinz, A. Mehnert, R. D. Kocalevent et al., "Assessment of depression severity with the PHQ-9 in cancer patients and in the general population," BMC Psychiatry, vol. 16, no. 1, pp. 1-8, 2016.

[10] S. W. M. C. Maass, C. Roorda, A. J. Berendsen, P. F. M. Verhaak, and G. H. De Bock, "The prevalence of longterm symptoms of depression and anxiety after breast cancer treatment: a systematic review," Maturitas, vol. 82, no. 1, pp. 100-108, 2015.

[11] C. Guan, S. Mohamed, K. Kaur, A. H. Sulaiman, N. Z. Zainal, and N. A. Taib, "Perceived distress and its association with depression and anxiety in breast cancer patients," PLoS One, vol. 12, no. 3, pp. 1-10, Article ID e0172975, 2017.

[12] S. Triberti, L. Savioni, V. Sebri, and G. Pravettoni, "eHealth for improving quality of life in breast cancer patients: a systematic review," Cancer Treatment Reviews, vol. 74, pp. 1-14, 2019.

[13] A. M. Berger, K. Mooney, A. Alvarez-Perez et al., "Cancerrelated fatigue, version 2.2015," Journal of the National Comprehensive Cancer Network, vol. 13, no. 8, pp. 1012-1039, 2015.

[14] H. J. G. Abrahams, M. F. M. Gielissen, C. A. H. H. V. M. Verhagen, and $\mathrm{H}$. Knoop, "The relationship of fatigue in breast cancer survivors with quality of life and factors to address in psychological interventions: a systematic review," Clinical Psychology Review, vol. 63, pp. 1-11, 2018.

[15] H. Abdel-Qadir, P. C. Austin, D. S. Lee et al., "A populationbased study of cardiovascular mortality following early-stage breast cancer," JAMA Cardiology, vol. 2, no. 1, pp. 88-93, 2017.

[16] M. Ewertz, L. H. Land, S. O. Dalton, D. Cronin-Fenton, and M. B. Jensen, "Influence of specific comorbidities on survival 
after early-stage breast cancer," Acta Oncologica, vol. 57, no. 1, pp. 129-134, 2018.

[17] World Health Assembly, "Cancer prevention and control in the context of an integrated approach," Resolution WHA70.12 Adopted by the Seventieth World Health Assembly, World Health Assembly, Geneva, Switzerland, 2017, http://apps.who. int/medicinedocs/documents/s23233en/s23233en.pdf\% 0Ahttp://apps.who.int/gb/ebwha/pdf_files/WHA70/A70_ R12-en.pdf.

[18] H. Greenlee, A. I. Neugut, L. Falci et al., "Association between complementary and alternative medicine use and breast cancer chemotherapy initiation," JAMA Oncology, vol. 2, no. 9, pp. 1170-1176, 2016.

[19] C. M. Witt, L. G. Balneaves, M. J. Cardoso et al., "A comprehensive definition for integrative oncology," JNCI Monographs, vol. 2017, no. 52, pp. 3-8, 2017.

[20] C. Jackson, "Trends in the use of complementary health approaches among adults in the United States: new data," Holistic Nursing Practice, vol. 29, no. 3, pp. 178-179, 2015.

[21] F. Naja, B. Anouti, H. Shatila, R. Akel, Y. Haibe, and A. Tfayli, "Prevalence and correlates of complementary and alternative medicine use among patients with lung cancer: a cross-sectional study in Beirut, Lebanon," Evidence-Based Complementary and Alternative Medicine, vol. 2017, Article ID 8434697, 11 pages, 2017.

[22] L. E. Carlson, E. Zelinski, K. Toivonen et al., "Mind-body therapies in cancer: what is the latest evidence?" Current Oncology Reports, vol. 19, no. 10, 2017.

[23] What is Art Therapy-American Art Therapy Association, American Art Therapy Association, Alexandria, VA, USA, 2017, https://arttherapy.org/about-art-therapy/.

[24] M. N. Azmawati, B. Boekhtiar, M. Zawiah, S. M. Aisah, W. L. Chiew, and R. Dalila, "The efficacy of art therapy on mental health outcomes among breast cancer patients: the current state of evidence based on randomised controlled trials," International Medical Journal Malaysia, vol. 17, no. 2, pp. 71-82, 2018.

[25] B. Wheeler, T. Lesiuk, D. Burns, B. Hanser, A. Rossetti, and M. Cassity, "Music therapy and music medicine studies in oncology: Part I: a comparison," Music and Medicine, vol. 11, no. 3, pp. 145-159, 2019.

[26] Y. Li, X. Xing, X. Shi et al., "The effectiveness of music therapy for patients with cancer: a systematic review and metaanalysis," Journal of Advanced Nursing, vol. 76, no. 5, pp. 1111-1123, 2020.

[27] I. Öster, A.-C. Svensk, E. Magnusson et al., "Art therapy improves coping resources: a randomized, controlled study among women with breast cancer," Palliat Support Care, vol. 4, no. 1, pp. 57-64, 2006.

[28] A. Puig, S. M. Lee, L. Goodwin, and P. A. Sherrard, "The efficacy of creative arts therapies to enhance emotional expression, spirituality, and psychological well-being of newly diagnosed stage I and stage II breast cancer patients: a preliminary study," The Arts in Psychotherapy, vol. 33, no. 3, pp. 218-228, 2006.

[29] A. Svensk, R. Sciences, and I. Öster, “Art therapy improves experienced quality of life among women undergoing treatment for breast cancer: a randomized controlled study," European Journal of Cancer Care, vol. 18, no. 1, pp. 69-77, 2009.

[30] K. E. Thyme, E. C. Sundin, and B. Wiberg, "Individual brief art therapy can be helpful for women with breast cancer: a randomized controlled clinical study," Palliative and Supportive Care, vol. 7, no. 1, pp. 87-95, 2009.
[31] D. A. Monti, K. M. Kash, E. J. S. Kunkel et al., "Changes in cerebral blood flow and anxiety associated with an 8-week mindfulness programme in women with breast cancer," Stress Heal, vol. 28, no. 5, pp. 397-407, 2012.

[32] D. A. Monti, K. M. Kash, E. J. Kunkel et al., "Psychosocial benefits of a novel mindfulness intervention versus standard support in distressed women with breast cancer," PsychoOncology, vol. 22, no. 11, pp. 2565-2575, 2013.

[33] S. H. Jang, S. Y. Kang, H. J. Lee, and S. Y. Lee, "Beneficial effect of mindfulness-based art therapy in patients with breast cancer-a randomized controlled trial," Explore: The Journal of Science \& Healing, vol. 12, no. 5, pp. 333-340, 2016.

[34] Z. Jalambadani and A. Borji, "Effectiveness of mindfulnessbased art therapy on healthy quality of life in women with breast cancer," Asia-Pacific Journal of Oncology Nursing, vol. 6, no. 2, p. 193, 2019.

[35] J. Czamanski-Cohen, J. F. Wiley, N. Sela, O. Caspi, and K. Weihs, "The role of emotional processing in art therapy (REPAT) for breast cancer patients," Journal of Psychosocial Oncology, vol. 37, no. 5, pp. 586-598, 2019.

[36] S. B. Hanser, S. Bauer-Wu, L. Kubicek et al., "Effects of a music therapy intervention on quality of life and distress in women with metastatic breast cancer," Journal of the Society for Integrative Oncology, vol. 4, no. 3, pp. 116-124, 2006.

[37] T. Bulfone, R. Quattrin, R. Zanotti, L. Regattin, and S. Brusaferro, "Effectiveness of music therapy for anxiety reduction in women with breast cancer in chemotherapy treatment," Holistic Nursing Practice, vol. 23, no. 4, pp. 238-242, 2009.

[38] P. G. Binns-Turner, L. L. Wilson, E. R. Pryor, G. L. Boyd, and C. A. Prickett, "Perioperative music and its effects on anxiety, hemodynamics, and pain in women undergoing mastectomy," AANA Journal, vol. 79, no. 4, pp. 21-27, 2011.

[39] X. M. Li, H. Yan, K. N. Zhou, S. N. Dang, D. L. Wang, and Y. P. Zhang, "Effects of music therapy on pain among female breast cancer patients after radical mastectomy: results from a randomized controlled trial," Breast Cancer Research and Treatment, vol. 128, no. 2, pp. 411-419, 2011.

[40] X. M. Li, K. N. Zhou, H. Yan, D. L. Wang, and Y. P. Zhang, "Effects of music therapy on anxiety of patients with breast cancer after radical mastectomy: a randomized clinical trial," Journal of Advanced Nursing, vol. 68, no. 5, pp. 1145-1155, 2012.

[41] K. N. Zhou, X. M. Li, H. Yan, S. N. Dang, and D. L. Wang, "Effects of music therapy on depression and duration of hospital stay of breast cancer patients after radical mastectomy," Chinese Medical Journal, vol. 124, no. 15, pp. 2321-2327, 2011.

[42] F. Romito, F. Lagattolla, C. Costanzo, F. Giotta, and V. Mattioli, "Music therapy and emotional expression during chemotherapy. How do breast cancer patients feel?" European Journal of Integrative Medicine, vol. 5, no. 5, pp. 438-442, 2013.

[43] J. B. Palmer, D. Lane, D. Mayo, M. Schluchter, and R. Leeming, "Effects of music therapy on anesthesia requirements and anxiety in women undergoing ambulatory breast surgery for cancer diagnosis and treatment: a randomized controlled trial," Journal of Clinical Oncology, vol. 33, no. 28, pp. 3162-3168, 2015.

[44] S. Moradian, C. Walshe, S. Shahidsales, M. R. Ghavam Nasiri, M. Pilling, and A. Molassiotis, "Nevasic audio program for the prevention of chemotherapy induced nausea and vomiting: a feasibility study using a randomized controlled trial design," 
European Journal of Oncology Nursing, vol. 19, no. 3, pp. 282-291, 2015.

[45] E. Karadag, Ö Uğur, and O. Çetinayak, "The effect of music listening intervention applied during radiation therapy on the anxiety and comfort level in women with early-stage breast cancer: a randomized controlled trial," European Journal of Integrative Medicine, vol. 27, pp. 39-44, 2019.

[46] F. C. Hsieh, N. F. Miao, I. J. Tseng et al., "Effect of home-based music intervention versus ambient music on breast cancer survivors in the community: a feasibility study in Taiwan," European Journal of Cancer Care, vol. 28, no. 4, pp. 1-10, 2019.

[47] E. Bilgin, O. Kirca, and M. Ozdogan, "Art therapies in cancer-a non-negligible beauty and benefit," Journal of Oncological Sciences, vol. 4, no. 1, pp. 47-48, 2018.

[48] D. Radl, M. Vita, N. Gerber, E. J. Gracely, and J. Bradt, "The effects of Self-Book $\odot$ art therapy on cancer-related distress in female cancer patients during active treatment: a randomized controlled trial," Psycho-Oncology, vol. 27, no. 9, pp. 20872095, 2018.

[49] L. Uttley, M. Stevenson, A. Scope, A. Rawdin, and A. Sutton, "The clinical and cost effectiveness of group art therapy for people with non-psychotic mental health disorders: a systematic review and cost-effectiveness analysis," BMC Psychiatry, vol. 15, no. 1, pp. 1-13, 2015.

[50] K. Boehm, H. Cramer, T. Staroszynski, and T. Ostermann, "Arts therapies for anxiety, depression, and quality of life in breast cancer patients: a systematic review and meta-analysis," Evidence-Based Complementary and Alternative Medicine, vol. 2014, Article ID 103297, 9 pages, 2014.

[51] Y. Tang, F. Fu, H. Gao, L. Shen, I. Chi, and Z. Bai, “Art therapy for anxiety, depression, and fatigue in females with breast cancer: a systematic review," Journal of Psychosocial Oncology, vol. 37, no. 1, pp. 79-95, 2019.

[52] S. Archer, S. Buxton, and D. Sheffield, "The effect of creative psychological interventions on psychological outcomes for adult cancer patients: a systematic review of randomised controlled trials," Psycho-Oncology, vol. 24, no. 1, pp. 1-10, 2015.

[53] T. Babikian, L. Zeltzer, V. Tachdjian et al., "Music as medicine: a review and historical perspective," Alternative and Complementary Therapies, vol. 19, no. 5, pp. 251-254, 2013.

[54] UK Cancer Research, "Music therapy," UK Cancer Research, London, UK, 2019, https://www.cancerresearchuk.org/aboutcancer/cancer-in-general/treatment/complementaryalternative-therapies/individual-therapies/music. 